Organo- and

Biocatalysis

\title{
Allylboration of Aldehydes
}

Key words

allylboration

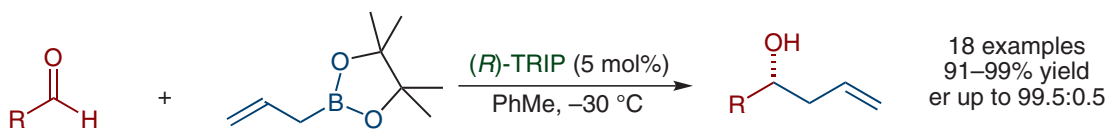

aldehydes

TRIP $\mathrm{R}=\mathrm{Ar}$, Alk<smiles></smiles><smiles>[R]C1=CC=C[PH]2(O1)OC(C)(C)C(C)(C)O2</smiles>

$(R)$-TRIP

proposed TS

Selected examples:
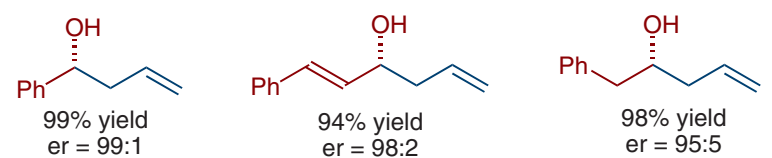<smiles>C=CC(C)C(O)c1ccccc1</smiles>

with (E)-boronate: $96 \%$ yield (anti), er $=98: 2$ with (Z)-boronate: $95 \%$ yield $(s y n)$, er $=97: 3$

Significance: A highly enantioselective allylboration of aldehydes catalyzed by the chiral Brønsted acid $(R)$-TRIP is reported by the authors. This transformation shows a broad substrate scope: aryl, heteroayrl, $\alpha, \beta$-unsaturated and aliphatic aldehydes can all be efficiently allylated. Furthermore, the crotylboration of benzaldehyde also proceeded smoothly with high diastereo- and enantioselectivity in the presence of this acid catalyst.
Comment: Simple starting materials and a commercially available catalyst make this protocol a useful and efficient method for the synthesis of enantioenriched homoallylic alcohols. A transition state where the boronate is activated by protonation of the boronate oxygen with a chiral phosphoric acid is proposed by the authors. To confirm this activation model, further mechanistic investigation may be required. 